4th Global Business Research Congress, May 24-25, 2018, Istanbul, Turkey.

\title{
THE GENDER WAGE INEQUALITY IN TURKEY
}

\author{
DOI: 10.17261/Pressacademia.2018.925 \\ PAP- V.7-2018(78)-p.408-413
}

\section{Gizem Kaya ${ }^{1}$, Raziye Selim ${ }^{2}$}

${ }^{1}$ Istanbul Technical University, Management Faculty, Management Engineering Department, 34367, Maçka, Istanbul, Turkey. kayagizem@itu.edu.tr, ORCID: 0000-0002-6870-7219

${ }^{2}$ Istanbul Technical University, Management Faculty, Management Engineering Department, 34367, Maçka, Istanbul, Turkey. selimraziy@itu.edu.tr, ORCID: 0000-0002-0277-1752

To cite this document

Kaya, G., Selim, R. (2018). The gender wage inequality in Turkey. PressAcademia Procedia (PAP), V.7, p.408-413.

Permemant link to this document: $h$ ttp://doi.org/10.17261/Pressacademia.2018.925

Copyright: Published by PressAcademia and limited licenced re-use rights only.

\section{ABSTRACT}

Purpose- To analyze the gender wage gap in Turkey and examine the differences by regions.

Methodology- Descriptive statistics, regression analyses by using household labor force survey of TURKSTAT of 2015 and Oaxaca decomposition analysis.

Findings- We use monthly salary as dependent variable; age of employee, years of schooling, experience, gender as independent variables to estimate the standard mincer wage equation (1974), then model is expanded by adding new variables such as firm size, regional dummies and occupations. By using expanded model, we run Oaxaca decomposition method to calculate the effect of gender discrimination and differences in human capital and occupational characteristics in wages.

Conclusion- We find significant effect of human capital variables on monthly salary, and there are significant differences in wages with respect to regions, gender and occupational characteristics. According to the Oaxaca decomposition method, despite the fact that women's human capital is better than men's, it is not enough to finish the wage inequality.

Keywords: Gender, wage, inequality, regional, gap.

JEL Codes: J16, J31, J71

\section{TÜRKIYY'DE CINSIYYTE BAĞLI ÜCRET EŞiTSIZLiĞi}

\section{ÖZET}

Amaç- Cinsiyete bağlı ücret eşitsizliğinin bileşenlerini analiz etmek ve bölgeler bakımından farklılıkları incelemek

Yöntem- Tanımlayıcı istatistikler, 2015 yılı TUík'in Hanehalkı İşücü Anketi kullanılarak yapılan regresyon analizleri ve Oaxaca ayrıştırma analizi

Bulgular- Çalışmada, Standart Mincer ücret denklemini (1974) tahmin etmede aylık ücret bağımlı değişken, işçinin yaşı, eğitim yılı, deneyim, cinsiyet bağımsız değişkenler olarak kullanılmıştır. Modele firma büyüklüğü, bölgesel kukla değişkenler ve meslek değişkenleri eklenerek model genişletilmiştir. Genişletilmiş model kullanılarak Oaxaca Ayrıştırma Analizi yardımıyla ücret farklılığının ne kadarının beşeri sermaye ve meslekten ne kadarının cinsiyet ayrımcılığından kaynaklandığı incelenmiştir.

Sonuç- Aylık ücret üzerinde beşeri sermaye değişkenlerinin etkisi anlamlı bulunmuştur. Ayrıca cinsiyete, bölgelere ve mesleklere göre ücret farkıııkları görülmüştür. Oaxaca ayrıştırma yöntemine göre kadınların beşeri sermayesinin erkeklere göre daha iyi olmasına rağmen ücret eşitsizliğinin tamamını gidermede etkili olmadığı bulunmuştur.

Anahtar Kelimeler: Cinsiyet, ücret, eşitsizlik, bölgesel, farklılık.

JEL Kodları: J16, J31, J71 


\section{GíRiş}

İsgücü piyasasına yönelik ücret eşitsizliklerinin nedenlerinden birisi cinsiyete dayalı ücret eşitsizlikleridir. Bu araştırmalarda kadın-erkek ücret farklııkları önceleri sadece demografik özelliklerdeki farkılıklarla açıklanırken veri kaynaklarııın zenginleşmesiyle çalışılan sektör, firma ölçeği, sendikalaşma durumu gibi firma yönlü etkenlerin açıklama gücü de analizlere eklenmiştir.

Bu çalışmada Türkiye'de daha önce yapılan araştırmalarda kadın erkek ücretleri arasında bulunan farkın, 2015 yııına gelindiğginde azalıp azalmadığı ve cinsiyet eşitsizliği açısından Türkiye bölgelerinin birbirine benzer olup olmadığı araştııılmıştır. Araştırma yöntemi kadın erkek ücret farkııı̆ııın ne kadarının yetkinliklerdeki farklııklardan ne kadarının piyasadaki fiyat farkıııklarından kaynaklandı̆̆ını bulmaya fırsat sunmaktadır. Bu amaçla Türkiye'de özel sektör çalışanlarının cinsiyete göre ücret, eğitim ve deneyim farklııkları incelenmiş, bölgelere göre farklılaşmaların olup olmadığı da araştırılmıştır.

\section{LITERATÜR INCELEMESI}

İşǚcü anketleri kullanılarak yapılan çalışmaların temeli Mincer (1974)'e dayanmaktadır. Mincer, kazançların belirlenmesinde okul eğitiminin ve iş deneyiminin katkılarını analiz etmiştir. Çalışmada eğitim ve deneyimin gelir üzerindeki katkısının pozitif yönde olacağını, fakat belirli bir deneyim yılından sonra deneyimin ücret üzerindeki etkisinin azalmaya başlayacağını savunmuştur.

Türkiye işgücü piyasası cinsiyete göre ücret eşitsizliği araştırmalarından Dayioğlu ve Kasnakoğlu (1997) 1987 Hanehalkı Gelir Dağılımı ve Harcama Anketini kullanarak kamu sektöründe cinsiyete göre ücret farklıı̆ının yok denecek kadar az olduğunu bulgulamıştır. Kadınların ortalama ücretlerinin erkeklerin ortalama ücretlerine oranını 0,96 bulmuşlardır. Tansel (2005), 1994 yılının Hanehalkı Harcama Anketini kullanarak özel sektörde tarım dışı çalışanlara dair kadın ve erkek ücret farkııı̆ı̆ıı araştırmıştır. Çalışmanın sonucuna göre kadınların ortalama ücretlerinin erkeklerin ortalama ücretlerine oranını 0,77 olarak bulmuştur. Ayrıca kadın erkek ücret farklııklarının sektöre göre değişebileceğini belirtmiştir.

Literatürde başka yöntemler olsa da genellikle ücret farkılığının nedenlerinin araştııılmasında Oaxaca (1973) ayrıştırma yöntemi kullanılmaktadır. Türkiye'de bu yöntem kullanılarak yapılan çalışmalardan birine Tansel'in (2005) çalışması örnek gösterilebilir. Tansel (2005) 1994 hanehalkı harcama anketlerinin veri seti ile eğitim, deneyim, bölge, kent ve kır değişkenlerini kullanarak regresyonlar tahmin etmiş, bu regresyonlar yardımıyla Oaxaca ayrıştırma yöntemine göre özel sektördeki ücret farkıııı̆ının \%42'sinin cinsiyet ayrımcılığına bağlı olduğunu belirtmiştir. Illkkaracan ve Selim ise (2007) 1994 yııını Kasım ayı referans alınarak yapılıp 1995 yılında oluşturulan veri setini kullanarak insan sermayesi kuramı değişkenleri olan eğitim, deneyim gibi değişkenlerin yanında meslek, sektör ve işyeri karakteristiklerini yansıtan işyeri ölçeği, sendikalı olma, bölge değişkenlerini kullanarak kadınların ortalama ücretlerinin erkeklerin ortalama ücretlerine oranının 0,91 olduğunu belirtmişlerdir.

Bunlar dışında daha küçük bölgeler bazında ücret farklııklarının nedenlerinin de araştıııldı̆ı çalışmalar vardır. Özkan ve Özkan (2010) Gaziantep ilinde yaptıkları anket sonucundan elde edilen verilerle ücret ayrımcılı̆ının nedenlerini 3 boyutta toplamıs ve bu boyutları ayrımcı faktörler, objektif faktörler ve seçici faktörler olarak adlandırmışlardır. Duruoğlu (2007) ise Bursa organize sanayi bölgesinde tekstil sektöründe kadınlara yönelik ücret ayrımclığının olduğunu ve cinsel ayırımcılığa dayanan istihdam politikalarının uygulandığıı belirtmiştir.

\section{VERI VE YÖNTEM}

Bu çalışmada Türkiye İstatistik Kurumu'nun (TUiK) 2015 yılına ait Hanehalkı İsgücü Anketleri (HIA) mikro veri seti kullanılmıştır. Araştırmaya istihdamda olan özel sektör çalışanları ve işteki durumu ücretli, maaşlı veya yevmiyeli tam zamanlı ücret beyanı olan çalışan kişiler dâhil edilmiştir.

Araştırmada bağımlı değişken olarak aylık ücret (TL) kullanılmış, bağımsız değişkenler olarak ise kişinin referans işteki deneyimi, referans işteki deneyimin karesi, eğitim yılı, NUTS1 düzeyindeki bölge değişkeni, cinsiyet, haftalık çalışma saati, meslek (ISCO 8) ve son olarak firma ölçeği değişkeni kullanılmıştır.

Araştırmada cinsiyete göre ücretlerin bölgeler arasında nasıl değiştiğinin incelenmesi için iki yönlü varyans analizi yapılmıştır. Ücret üzerindeki bağımsız değişkenlerin etkisini görmek içinse öncelikle beşeri sermaye değişkenleri için regresyon analizi sonrasında tüm değişkenler kullanılarak regresyon analizi gerçekleştirilmiştir. Kadın erkek ücret farklııklarının ne kadarının beşeri sermayedeki farklııklardan açıklandığını ne kadarııı açıklanamadığını bulmak amacıyla Oaxaca ayrıştırma yöntemi kullanıımıştır.

Yukarıda sözü edilen beşeri sermaye değişkenleri kullanılarak oluşturulan denklem (1) aşağıdaki gibi olacaktır:

$$
\operatorname{LnW}=B_{0}+B_{1} S+B_{2} E+B_{3} E^{2}
$$

Burada LnW ücret değiş̧keninin logaritmasını, S kişinin eğitim yılını, E ise deneyim yılını göstermektedir. Denklem Standart Mincer denklemi literatürüne uygun olarak yarı logaritmik formda kurulmuştur.

Diğer değişkenlerin de eklendiği genişletilmiş denklem (2) ise aşağıdaki gibidir:

$$
L n W=B_{0}+B_{1} S+B_{2} E+B_{3} E^{2}+B_{4} H+B_{5} G+B_{6} G * S+\sum_{i=7}^{9} B_{i} F+\sum_{j=10}^{18} B_{j} M+\sum_{q=19}^{27} B_{q} R
$$


Burada G cinsiyet, F firma büyüklüğü (Küçük (<10) -Orta (10 - 249<) -Büyük Ölçekli (-250>0), M meslek ve R ise bölge kukla değişkenlerini temsil etmektedir.

Oaxaca (1973) ayrışıırması ayrı ayrı kadınlar ve erkeklere göre tahmin edilen beşeri sermaye denklemlerinden yola çıkarak ücret farklıı̆ının ne kadarının beşeri sermaye kaynaklı olduğunu araştırmak için yardımcı olmaktadır. Ayrıştırma yöntemi aşağıdaki (3) gibidir:

$$
\overline{\ln W_{m}}-\overline{\ln W_{f}}=\sum_{i=1}^{n}\left(\overline{X_{m i}}-\bar{X}_{f i}\right) \cdot \beta_{m i}+\sum_{i=1}^{n}\left(\beta_{m i}-\beta_{f i}\right) \cdot \bar{X}_{f}
$$

Burada B, erkekler (m) ve kadınlar (f) için ayrı ayrı beşeri sermaye denklemi tahmininden elde edilen deneyim ve eğitim yılı için regresyon katsayılarını göstermektedir. Ortalamalar ise sırasıyla erkek ve kadınlar için deneyim ve eğitim yılı ortalamalarını temsil etmektedir. Yukarıdaki denkleme göre deneyim ve eğitim yılı için ayrı ayrı hesaplamalar bulunacak ve ücret farkı sözel olarak şu şekilde açıklanacaktır: Ücret farklıı̆̆ı= yetkinlik farkı (açıklanan kısım) + ayrımcılık (açıklanamayan kısım)

\section{BULGULAR}

Analizde yer alan 68948 bireyin \% 76'sını erkekler \% 24'ünü ise kadınlar oluşturmaktadır. Çalışmaya ilişkin tanımlayıcı istatistikler Tablo 1 ve Tablo 2'de sunulmuştur. Tablo 1'e göre 2015 yılında özel sektör çalışanlarında aylık ortalama ücret 1493,5 TL olarak elde edilmiştir. Kadınların ortalama ücretleri erkeklerin ortalama ücretlerine oranı 0.90 bulunmuştur. Referans işteki ortalama deneyim yılı ve ortalama haftalık çalışma saatinin kadınlarda erkeklere oranla daha az olduğu gözlemlenmiştir. Eğitim yılı ortalama bakımından kadınlarda erkeklere oranla daha yüksek olduğu bulunmuştur.

\section{Tablo 1: Tanımlayıcı İstatistikler}

\begin{tabular}{|l|l|l|l|}
\hline & Toplam & Erkek & Kadın \\
\hline Aylık Ücret & 1493,5 & 1531,8 & 1379,1 \\
& $(1333,7)$ & $(1341,7)$ & $(1302,8)$ \\
\hline Referans İşteki Deneyim & 4,0 & 4,2 & 3,3 \\
& $(5,2)$ & $(5,4)$ & $(4,3)$ \\
\hline Eğitim Yılı & 9,4 & 9,1 & 10,4 \\
& $(4,4)$ & $(4,2)$ & $(4,8)$ \\
\hline Haftalık Çalışma Saati & 51,9 & 52,8 & 49,1 \\
& $(10,3)$ & $(10,5)$ & $(9,2)$ \\
\hline
\end{tabular}

Araştırmamızda yer alan istihdamdaki 68948 kişinin bölgelere göre dağılımı şu şekildedir: İstanbul (İstanbul) \% 15,8; Batı Marmara (TekirdağBalıkesir) \% 7,9; Ege ('̇zmir-Aydın-Manisa) \%12,8; Doğu Marmara (Bursa-Kocaeli) \% 11,0; Batı Anadolu (Ankara-Konya) \% 12,7; Akdeniz (Antalya-Adana-Hatay) \% 10,8; Orta Anadolu (Kırıkkale-Kayseri) \% 5,4; Batı Karadeniz (Zonguldak-Kastamonu-Samsun) \% 6,3; Doğu Karadeniz (Trabzon) \%3,1; Kuzeydoğu Anadolu (Erzurum- Ağrı) \%2,9; Ortadoğu Anadolu (Malatya-Van) \% 4.5; Güneydoğu Anadolu (Şanlıurfa Gaziantep-Mardin) \%7.

Araştırmada mesleklere göre özel sektör çalışanlarının dağılımı yüzde 3,3 Yöneticiler; yüzde 5,2 ile Profesyonel meslek mensupları; yüzde 6,6 ile Teknisyenler, teknikerler ve yardımcı profesyonel meslek mensupları; yüzde 9,0 ile Büro hizmetlerinde çalışan elemanlar; yüzde 22,2 ile Hizmet ve satış elemanları; yüzde 1,4 ile Nitelikli tarım, ormancılık ve su ürünleri çalışanları; yüzde 20,0 ile Sanatkârlar ve ilgili işlerde çalışanlar; yüzde 14,5 ile Tesis ve makine operatörleri ve montajcıları; yüzde 18,0 ile Nitelik gerektirmeyen işlerde çalışanlar şeklindedir. Bu rakamlara göre en fazla özel sektörde istihdamın hizmet ve satış elemanlarını aldığı, en az istihdamın ise nitelikli tarım, ormancılık ve su ürünleri çalışanları olduğu gözlemlenmiştir.

Araştırmada yer alan kişilerin çoğunluğu yüzde 30.1 ile ilkokul, yüzde 22.9 ile ortaokul veya ilköğretim mezunlarıdır. Bunları yüzde 17.4 ile yüksekokul ve üzeri, yüzde 14.1 ile mesleki veya teknik lise yüzde 12 ile genel lise ve son olarak da \%3.6 ile bir okul bitirmeyenler izlemektedir. 
Tablo 2: Bölgelere Göre Ücretler

\begin{tabular}{|c|c|c|c|}
\hline & Toplam & Erkek & Kadın \\
\hline \multicolumn{4}{|l|}{ Bölge } \\
\hline \multirow[t]{3}{*}{ İstanbul } & 1843,1 & 1884,7 & 1745,0 \\
\hline & $(2166,6)$ & $(2222,9)$ & $(2024,6)$ \\
\hline & & $70,2 \%$ & $29,8 \%$ \\
\hline \multirow[t]{3}{*}{ Batı Marmara } & 1303,7 & 1400,7 & 1105,2 \\
\hline & $(687,5)$ & $(952,9)$ & $(500,3)$ \\
\hline & & $70,2 \%$ & $29,8 \%$ \\
\hline \multirow[t]{3}{*}{ Ege } & 1341,9 & 1387,8 & 1198,8 \\
\hline & $(903,1)$ & $(737,1)$ & $(749,4)$ \\
\hline & & $70,9 \%$ & $29,1 \%$ \\
\hline \multirow[t]{3}{*}{ Doğu Marmara } & 1477,7 & 1564,2 & 1244,1 \\
\hline & $(940,4)$ & $(999,6)$ & $(706,6)$ \\
\hline & & $73,0 \%$ & $27,0 \%$ \\
\hline \multirow[t]{3}{*}{ Batı Anadolu } & 1514,9 & 1554,2 & 1381,0 \\
\hline & $(1159,8)$ & $(1198,4)$ & $(1006,1)$ \\
\hline & & $77,3 \%$ & $22,7 \%$ \\
\hline \multirow[t]{3}{*}{ Akdeniz } & 1280,4 & 1331,4 & 1119,0 \\
\hline & $(842,4)$ & $(902,1)$ & $(588,3)$ \\
\hline & & $76,0 \%$ & $24,0 \%$ \\
\hline \multirow[t]{3}{*}{ Orta Anadolu } & 1237,1 & 1279,7 & 1047,6 \\
\hline & $(629,9)$ & $(648,3)$ & $(498,3)$ \\
\hline & & $81,6 \%$ & $18,4 \%$ \\
\hline \multirow[t]{3}{*}{ Batı Karadeniz } & 1260,0 & 1331,2 & 1011,9 \\
\hline & $(871,1)$ & $(937,1)$ & $(513,8)$ \\
\hline & & $77,7 \%$ & $22,3 \%$ \\
\hline \multirow[t]{3}{*}{ Doğu Karadeniz } & 1268,0 & 1309,9 & 1122,9 \\
\hline & $(651,1)$ & $(661,7)$ & $(591,3)$ \\
\hline & & $77,6 \%$ & $22,4 \%$ \\
\hline \multirow{3}{*}{$\begin{array}{l}\text { Kuzeydoğu } \\
\text { Anadolu }\end{array}$} & 1274,6 & & \\
\hline & $(671,8)$ & $\begin{array}{l}1296,8 \\
(686,9)\end{array}$ & $(465,5)$ \\
\hline & & $90,2 \%$ & $9,8 \%$ \\
\hline \multirow[t]{3}{*}{$\begin{array}{l}\text { Ortadoğu } \\
\text { Anadolu }\end{array}$} & 1197,5 & 1227,0 & 997,3 \\
\hline & $(660,5)$ & $(685,9)$ & $(397,9)$ \\
\hline & & $87,2 \%$ & $12,8 \%$ \\
\hline \multirow[t]{3}{*}{$\begin{array}{l}\text { Güneydoğu } \\
\text { Anadolu }\end{array}$} & 1167,5 & 1180,3 & 1091,3 \\
\hline & $(928,6)$ & $(898,2)$ & $(1089,9)$ \\
\hline & & $85,6 \%$ & $14,4 \%$ \\
\hline
\end{tabular}

Tablo 2'ye göre ortalama ücretlerin en çok i̇stanbul bölgesinde en az ise Güneydoğu Anadolu bölgesinde olduğu gözlemlenmiştir. Fakat bu bölgelerde kadın erkek ücret farkının da diğer bölgelere göre daha az olduğu gözlemlenmektedir. Ücret farkı en fazla Doğu Marmara, Batı Marmara ve Batı Karadeniz bölgelerinde görülmüştür. Kadın istihdamı ise en az Kuzeydoğu Anadolu bölgesinde, en fazla ise Ege bölgesinde olduğu oransal olarak gözlemlenmiştir. Bu ortalamaların bölgelere göre, cinsiyete göre, bölge ve cinsiyete göre farklılık gösterip göstermediğinin testi için iki yönlü varyans analizi yapılmıştır. Test sonucuna göre Türkiye genelinde kadın-erkek ücretlerinin ortalama olarak farklı olduğu ( $F=244,62)$, bölgeler arasında en az bir bölgenin ortalama ücretinin diğer bölgelerden farklı olduğunu $(F=167,68)$ ve aynı şekilde bölgeler arasında cinsiyete göre ortalama ücretlerin de farklılaştığı görülmüştür $(F=3,63)$.

İki yönlü varyans analizi sonrası yapılan post-hoc testlerinden Tukey testi sonucuna göre kadınların ortalama maaşı Orta Anadolu-Batı Karadeniz-Ortadoğu Anadolu bölgelerinde benzer; aynı şekilde Batı Marmara-Ege-Akdeniz-Doğu Karadeniz Kuzeydoğu Anadolu - Güneydoğu Anadolu bölgelerinde de birbirine yakın olduğu gözlemlenmiştir. Erkeklerin ortalama maaşı ise Akdeniz-Batı Karadeniz-Doğu Karadeniz-Kuzeydoğu Anadolu bölgelerinde benzer; ayrıca Batı Marmara-Ege bölgelerinde ve Batı Anadolu-Doğu Marmara bölgelerinde de yakın olduğu gözlemlenmiştir. Bu durumda ücretlerde mekânsal bir etkinin varlığından söz edilebilir.

Tablo 3 regresyon analizi sonuçlarını göstermektedir. Regresyonda berk standart hatalar kullanılarak değişen varyans probleminden kaçınılmıştır. Katsayıların hepsi 0.05 anlamlılık düzeyine göre istatistiksel olarak anlamlı bulunmuştur. Beşeri sermaye denklemine göre eğitim ve deneyimin ücretler üzerindeki katkısı pozitif iken aynı işyerinde belirli yıldan sonra deneyimin katsayısı negatif bulunmuştur. Bu yıl 25 yıldır. Genişletilmiş model incelendiğinde ise yine yıl bakımından 25 yıl sonra deneyimin artmasıyla beraber ücretin artış oranında azalmalar görüleceği bulunmuștur. Regresyon analizinde yine erkeklerin ortalama maaşı kadınlara oranla yüksek olduğu, bölge bakımından İstanbul bölgesinde ücretlerin diğer bölgelere göre daha fazla olduğu ve yine en az Güneydoğu Anadolu bölgesinde olduğu gözlemlenmiştir. Yöneticilerin ortalama ücretlerinin diğer çalışanlardan fazla olduğu yine en az ortalama ücretlerin Nitelikli tarım, ormancılık ve su ürünleri çalışanlarında olduğu gözlemlenmiştir. Cinsiyet*Eğitim değişkeninin katsayısı ise negatif değer almaktadır. Bu durum erkeklerin bir yıl daha fazla okumasının ücret üzerindeki katkııının kadınların bir yıl daha fazla okumasının ücret üzerindeki katkısından daha az olduğunu göstermektedir.

Tablo 4'te ise beşeri sermaye denklemine göre Oaxaca ayrıştırmasının sonuçları yer almaktadır. Toplam değerlerin pozitif olması erkeklerin ortalama ücretlerinin kadınlardan fazla olduğunu göstermektedir. En az ücret farkı i̇stanbul ve Ege bölgelerinde, en fazla ise Batı Marmara, Doğu Marmara ve Batı Karadeniz bölgelerinde gözlemlenmiştir. Ücret farkının beşeri sermaye yani eğitim ve deneyim ile açıklanan kısmının negatif olması kadınların lehinedir. Başka bir deyişle kadınların beşeri sermayeleri daha iyi olmasına rağmen açıklanmayan kısımdan yani piyasadaki ücret farklılıklarından dolayı erkeklerin ortalama ücretleri daha yüksektir. Bu durum sadece Batı Karadeniz, Doğu Marmara ve Batı Marmara bölgelerinde farklıdır. Bu durumun bu bölgelerde böyle olmasının nedeni erkeklerin deneyim ortalamalarının kadınlara göre üstünlüğünün etkisi, kadınların eğitim ortalamasındaki erkeklere göre üstünlüğünü bastırmasıdır. Diğer bölgelerde kadınların ortalama olarak daha fazla okuması ortalama deneyim yılındaki erkek üstünlüğünü geçmekte ve beşeri sermaye katkısı kadınların lehine ücret farkını azaltıcı yönde olmaktadır. 
Tablo 3: Regresyon Analizi Sonuçları

\begin{tabular}{|c|c|c|}
\hline & $\begin{array}{l}\text { Beşeri } \\
\text { Sermaye } \\
\text { Modeli }\end{array}$ & $\begin{array}{l}\text { Genişletilmiş } \\
\text { Model }\end{array}$ \\
\hline Referans İşteki Ortalama & $0,035 * * *$ & $0,024 * * *$ \\
\hline $\begin{array}{l}\text { Deneyim } \\
\text { Referans }\end{array}$ & & \\
\hline $\begin{array}{l}\text { Referans İşteki Ortalama } \\
\text { Deneyimin Karesi }\end{array}$ & $-0,001 * * *$ & $-0,0005^{* * *}$ \\
\hline Eğitim Yılı & $0,039 * * *$ & $0,024 * * *$ \\
\hline Haftalık Ortalama Çalışma Saati & & $0,002 * * *$ \\
\hline Cinsiyet & & \\
\hline Erkek & & $0,249 * * *$ \\
\hline Cinsiyet*Eğitim & & $-0,008 * * *$ \\
\hline Firma Ölçeği & & \\
\hline Orta Ölçekli Firma & & $0,170 * * *$ \\
\hline Büyük Ölçekli Firma & & $0,130 * * *$ \\
\hline Bölge & & \\
\hline Batı Marmara & & $-0,178^{* * *}$ \\
\hline Ege & & $-0,176 * * *$ \\
\hline Doğu Marmara & & $-0,122 * * *$ \\
\hline Batı Anadolu & & $-0,132 * * *$ \\
\hline Akdeniz & & $-0,219 * * *$ \\
\hline Orta Anadolu & & $-0,206 * * *$ \\
\hline Batı Karadeniz & & $-0,233 * * *$ \\
\hline Doğu Karadeniz & & $-0,210 * * *$ \\
\hline Kuzeydoğu Anadolu & & $-0,190 * * *$ \\
\hline Ortadoğu Anadolu & & $-0,207 * * *$ \\
\hline Güneydoğu Anadolu & & $-0,297 * * *$ \\
\hline Meslek & & \\
\hline Profesyonel meslek & & $-0,246 * * *$ \\
\hline $\begin{array}{l}\text { Teknisyenler ve yardımcı } \\
\text { profesyonel meslek }\end{array}$ & & $-0,560 * * *$ \\
\hline Büro hizmetleri & & $-0,687 * * *$ \\
\hline Hizmet ve satış & & $-0,789 * * *$ \\
\hline Nitelikli tarım, ormancılık ve su & & $-0,815^{* * *}$ \\
\hline Sanatkârlar ve ilgili işler & & $-0,720 * * *$ \\
\hline Tesis ve makine operatörleri & & $-0,725 * * *$ \\
\hline Nitelik gerektirmeyen işler & & $-0,826 * * *$ \\
\hline Sabit & $6,642 * * *$ & $7,320 * * *$ \\
\hline Düzeltilmiş R2 & $18,6 \%$ & $38,16 \%$ \\
\hline $\mathbf{N}$ & 68948 & 68948 \\
\hline
\end{tabular}

Tablo 4: Oaxaca Ayrıştırması Sonuçları

\begin{tabular}{|l|l|l|l|}
\hline & $\begin{array}{l}\text { Beşeri } \\
\text { Sermaye }\end{array}$ & $\begin{array}{l}\text { Açıklanamayan } \\
\text { Kısım }\end{array}$ & Toplam \\
\hline Batı Karadeniz & 0,023 & 0,229 & 0,252 \\
Ortadoğu Anadolu & $-0,037$ & 0,222 & 0,185 \\
Kuzeydoğu Anadolu & $-0,053$ & 0,210 & 0,157 \\
Orta Anadolu & $-0,005$ & 0,205 & 0,199 \\
Doğu Marmara & 0,009 & 0,204 & 0,213 \\
Batı Anadolu & $-0,048$ & 0,190 & 0,142 \\
Akdeniz & $-0,023$ & 0,187 & 0,165 \\
Batı Marmara & 0,025 & 0,183 & 0,208 \\
Doğu Karadeniz & $-0,022$ & 0,176 & 0,154 \\
Güneydoğu Anadolu & $-0,003$ & 0,163 & 0,161 \\
Türkiye & $-0,027$ & 0,163 & 0,135 \\
Ege & $-0,009$ & 0,156 & 0,148 \\
İstanbul & $-0,064$ & 0,150 & 0,086 \\
\hline
\end{tabular}

\section{SONUÇ}

Bu çalışmada Türkiye genelinde ve bölgeler bazında cinsiyete göre ücretlerde farklılıklar araştırılmıştır. 2015 yılının Hanehalkı İşgücü mikro veri seti kullanılarak özel sektör çalışanlarına yönelik yapılan çalışmada erkeklerin ortalama ücretlerinin kadınların ortalama ücretlerinden daha fazla olduğu gözlemlenmiştir. Kadınlarda eğitim yılı ortalaması daha yüksek iken, erkeklerde deneyim yılı ortalaması daha yüksektir. Bölgeler bakımından ücret farkının en fazla olduğu bölgeler Batı Karadeniz, Doğu Marmara, Batı Marmara bölgeleri en az olduğu bölgeler ise İstanbul ve Ege bölgeleridir. Doğu Karadeniz, Batı Marmara ve Doğu Marmara hariç diğer bölgelerde kadınların beşeri sermayesi erkeklere göre daha iyi olmasına rağmen ücret farkını kapatmada yeterli olmadığı görülmüştür. Batı Karadeniz ve Güneydoğu Anadolu'da sırasıyla 1011,9 TL ve 1091,3 TL ile diğer bölgelerden düşük ücret ortalaması, İstanbul bölgesinde ise 1745,0 TL ile diğer bölgelerden yüksek ücret ortalaması gözlemlenmiştir. Bu çalışma Türkiye'de bölgeler bakımından cinsiyete göre ücret eşitsizliklerinin nedenlerini ve yapısını ayrıntılı biçimde ele aldığından literatüre katkısı olacağı düşünülmektedir. 


\section{KAYNAKLAR}

Dayioglu, M., Kasnakoglu, Z. (1997). Kentsel kesimde kadın ve erkeklerin isgücüne katılımları ve kazanç farklılıkları. METU Studies 24(3): 329361.

Duruoğlu, T. (2007). Emek piyasasında cinsiyetçi ücret ayrımı: Bursa Organize Sanayi bölgesinde bir araştırma. İletişim kuram ve araştırma dergisi, (24).

İlkkaracan, İ., Selim, R. (2007). The gender wage gap in the Turkish labor market. Labour 21(3): 563-593.

Mincer, J. (1974). Schooling, experience, and earnings. Human Behavior and Social Institutions No. 2.

Oaxaca, R. (1973). Male female wage differentials in urban labor markets. International Economic Review 14(3): 693-709.

Özkan, G. S., Özkan, B. (2010). Kadın çalışanlara yönelik ücret ayrımcılığı ve kadın ücretlerinin belirleyicilerine yönelik bir araştırma. Çalışma ve Toplum, 1(24), 91-104.

Tansel, A. (2005). Public-private employment choice, wage differentials and gender in Turkey. Economic Development and Cultural Change 53(2): 453-477. 